This PDF is a selection from an out-of-print volume from the National Bureau of Economic Research

Volume Title: International Economic Transactions: Issues in Measurement and Empirical Research

Volume Author/Editor: Peter Hooper and J. David Richardson, editors

Volume Publisher: University of Chicago Press

Volume ISBN: 0-226-35135-1

Volume URL: http://www.nber.org/books/hoop91-1

Conference Date: November 3-4, 1989

Publication Date: January 1991

Chapter Title: Quality Issues Affecting the Compilation of the U.S. Merchandise Trade Statistics

Chapter Author: Bruce C. Walter

Chapter URL: http://www.nber.org/chapters/c8428

Chapter pages in book: (p. 89 - 105) 


\title{
Quality Issues Affecting the Compilation of the U.S. Merchandise Trade Statistics
}

\author{
Bruce C. Walter
}

\subsection{Introduction}

After statistics on population, statistics on foreign trade are among the oldest sets of statistics continuously compiled by the United States government. The Treasury Department first compiled and published estimates of the balance of trade as far back as 1790 . Statistics compiled from actual trade documents first became available in 1820 . In recent years, however, with the dramatic increase of interest in the U.S. international trade position, the U.S. foreign trade statistics have come under critical scrutiny. The government has significantly increased its efforts to adapt the trade statistics program to the changing patterns of international trade and to produce the most accurate and timely statistics possible. To this end a number of significant changes and proposed changes have been undertaken in the ways in which the trade statistics are collected, compiled, and presented. In this paper I will discuss these changes and their impact on the quality of the trade statistics. I will also discuss other quality issues that have yet to be addressed and will offer some outlook for addressing them.

\subsection{A Brief Overview of the Trade Statistics Program}

In the United States, the Bureau of the Census is the agency responsible for processing, compiling, and publishing statistics on U.S. exports and imports of merchandise. These statistics, in the form of a monthly census or counting of individual merchandise shipments, do not include reports on trade in services or capital flows but cover only flows of merchandise.

Bruce C. Walter is assistant chief for methodology and quality assurance in the Foreign Trade Division of the U.S. Bureau of the Census. 
The U.S. Customs Service also plays a vital role as the collection agent for the trade statistics. The Customs Service collects the basic documentation reflecting individual shipments of merchandise from exporters and importers at over 400 U.S. ports of exit and entry and transmits statistical information on these shipments to the Census Bureau on a daily basis. The Customs Service also checks the quality of the reporting by verifying the accuracy of certain statistical data.

The transmittal of data to the Census Bureau takes two forms: automated transmissions and mailings of paper documents. For import transactions, the Customs Service each month electronically transmits over 800,000 lines of data to the Census Bureau for processing. In addition, it mails 200,000 paper documents to the Census Bureau for data entry processing. For exports, U.S. exporters and freight forwarders transmit about 20 percent of total transactions directly to the Census Bureau in electronic or summary reports. Another 30 percent of export transactions are captured under an agreement with Canada that allows Canadian import data to be utilized for U.S. exports to Canada. The remaining 50 percent of export transactions are compiled by the Census Bureau from the approximately 500,000 export documents collected from exporters each month by the Customs Service.

No formal documentation is required for nontextile import transactions valued from $\$ 1$ to $\$ 1,250$ or for textile import shipments valued from $\$ 1$ to $\$ 250$. Export shipments valued from $\$ 1$ to $\$ 2,500$ require no documentation. The value of these low-value transactions is estimated by country of origin or destination, on the basis of historical relationships of low-value to total shipments established from independent studies.

The Census Bureau staff checks the data reported on documents for completeness. Incomplete documents are referred to Census Bureau commodity analysts for resolution or returned to the Customs Service or shippers for additional information. Following the review operation, all documents are microfilmed for record-keeping purposes.

The statistical data on the documents are then captured on electronic keyentry equipment. A number of validity checks are performed to minimize keyentry and reporting errors. Currently over 500,000 individual export records (each individual commodity line on a document represents a separate record) and about 250,000 import records are keyed each month.

Import and export data which are received via automated means are handled more directly. Upon receipt, the Census Bureau subjects automated data records to computer checks, which verify the completeness and accuracy of the data. If problems are uncovered, the Census Bureau immediately contacts the exporter or freight forwarder, or in the case of imports, the Customs Service, for resolution. The Census Bureau has worked with the Customs Service to incorporate many of its statistical edits into the Customs automated import system. This allows statistical editing to be performed as soon as an auto- 
mated importer or broker enters information into the Customs system. After receipt and verification, the Census Bureau merges all directly submitted data with the Census keyed data for further screening by an extensive battery of Census computer edits. The computer edit screens are run on a weekly basis, and records intercepted during these edits are resolved for recycling into the following week's processing. Problems uncovered near the end of the monthly processing cycle, however, must be held for inclusion in the following month's cycle. These records generally account for less than one percent of value.

After completion of the processing cycle, the data are summarized monthly for release to the public. The public release, which is scheduled for about 45 days after the close of the subject month, begins with release of the overall import, export, and trade balance figures, followed closely by release of more than 100 separate reports in various arrangements.

\subsection{Present Status}

In recent years the volume of U.S. trade has expanded greatly, and the size of the U.S. trade deficit has become a major economic and political concern. In the 20-year period between 1969 and 1989, the value of imports plus exports has increased over 1000 percent, from $\$ 74$ billion in 1969 to $\$ 837$ billion in 1989, and from 8 to 16 percent of GNP. The trade balance during this period has changed from a surplus of $\$ 1.3$ billion in 1969 to a deficit of $\$ 109$ billion in 1989. As a result, interest in the Census Bureau's foreign trade statistics program has mushroomed, and the monthly trade balance has become one of the most publicized and scrutinized of the nation's economic indicators. In recent years release of the monthly trade statistics seems to have had a significant effect on the stock and bond markets.

It was natural for users to become concerned about the quality of the trade data, given increasing interest and the limited resources available for overseeing the production of the data. Problems with the timeliness of the import data and a growing undercount of U.S. exports to Canada cast doubts on the accuracy of the trade statistics. Even the U.S. Congress voiced its concern with the ability of the statistics to accurately measure the U.S. trade position. In the Omnibus Trade and Competitiveness Act of 1988, Congress specifically mandated that the monthly trade totals be expressed in constant dollars as well as current dollars, and that U.S. trade be expressed in terms of the International Harmonized System of commodity classification rather than the national classifications then in use.

With this increased scrutiny and criticism of the data, the Census Bureau has significantly increased its efforts to adapt the trade statistics program to the changing patterns of international trade and to produce more accurate and 
timely statistics. To this end it recently has introduced significant changes and has proposed more changes in the way in which the trade numbers are compiled and presented.

\subsection{Recent Quality Improvements}

Producing useful, high-quality trade statistics is complicated by the different requirements of the many users of the statistics. For national accounting and general economic policy purposes, it is important to have accurate aggregate estimates of exports and imports. To monitor trade policies and provide analyses to support trade negotiations or study trade markets, however, it is important to have accurate product and country detail, often for categories that cannot be determined in advance. For the purposes of this paper, I will look at recent quality improvement efforts on two levels: broad macroissues and microissues involving problems with the detail.

\subsection{Macroissues}

Since 1986, several major issues affecting the overall quality of the trade statistics have been identified, addressed, and resolved to varying degrees.

\subsubsection{Timing}

Timing problems occur when the statistics do not accurately reflect import or export transactions in the time period in which they occur. During the late 1970 s and early 1980s, changes in the Customs Service's requirements for and handling of import documents, coupled with dramatic increases in import transactions, resulted in large numbers of documents being transmitted too late for the Census Bureau to process and include them in the proper month's statistics. The late documents were then carried over into a subsequent month's data. By late 1985, when the Census Bureau first recognized the extent of the problem, more than 50 percent of some months' import data represented "carryover." Equally as harmful to the quality of the statistics was the fact that carryover was volatile as well as large. In late 1985 and early 1986 , carryover levels ranged from 30 percent to 55 percent. During the same time period, export carryover ranged between 8 and 14 percent. The Census $\mathrm{Bu}-$ reau was forced to discontinue seasonal adjustment of the foreign trade data because of the problems in determining true seasonality.

During the next two years, the Census Bureau and the Customs Service worked closely to change Customs collection and Census Bureau processing procedures to reduce the size of the carryover. By the end of 1987, these changes had allowed the Census Bureau to reduce carryover to about 20 percent.

Finally, with the March 1988 statistics, the Census Bureau announced that it would delay release of the trade statistics by two weeks to allow more time 
for receipt and processing of both the import and export documents. This delay, coupled with the earlier Census Bureau and Customs Service procedural changes, dropped the carryover level to under 5 percent. With recent advances in automated reporting of the statistics, the level has been further reduced to between 2 and 3 percent.

With the April 1988 statistics, the Census Bureau introduced two additional changes to further minimize the effect of carryover. First, it instituted a revision of prior-month trade totals to reallocate any remaining carryover to the proper statistical month. This revision further reduced carryover in the revised month to under 1 percent. Second, the Census Bureau reinstituted seasonal adjustment of the import and export totals at the overall level and for six broad end-use product categories. ${ }^{1}$

\subsubsection{Undocumented Exports to Canada}

Concern about missing export documentation has long been an issue. The Customs Service program for collecting and verifying export documents does not receive the same degree of attention and resources as the import program, since administration of tariffs and enforcement of trade agreements are major Customs mandates. Particularly along the extensive open U.S. -Canadian border with its heavy volume of trade, the undercount of exports became a major concern.

This concern was precipitated by a 1971 agreement between the Census Bureau and Statistics Canada to conduct an annual reconciliation of discrepancies in the trade data of the two countries and to reach a mutually agreedupon estimate of the U.S.-Canada trade balance.

Over the next 17 years reconciliation studies showed discrepancies between U.S. exports and Canadian imports growing increasingly wider. In 1970 and 1971 the difference for northbound trade stood at $\$ 400$ million, or about 4.5 percent. In 1978 the difference rose to $\$ 2.3$ billion, just over 7 percent of northbound trade. By 1986 , the discrepancy had skyrocketed to $\$ 11.5$ billion, over 20 percent of trade. The 1986 reconciliation study also revealed that, as in previous years, the major contributor to the discrepancy was the nonreceipt of U.S. export documents, in an amount that was estimated in 1986 to be about $\$ 10.2$ billion, or one in every five dollars of U.S. exports to Canada.

The extreme differences observed in the U.S.-Canada trade statistics during these reconciliation studies led officials from both countries to agree to a drastic plan of action.

In March 1987 the heads of the U.S. and Canadian customs and statistical agencies met in Washington to discuss ways of improving the accuracy of the trade statistics reported by the two countries. The agencies agreed that the best short-term solution was to share current import information and to use it to supplement undercounted export data.

1. Increased levels of seasonal adjustment are discussed in section 3.6.2. 
These initial supplements for undocumented U.S. exports to Canada included adjustments to published totals for all months in 1987 and annual adjustments back to 1970. Each subsequent month's statistics (published prior to January 1990) included this adjustment. These adjustments, however, were applied only at the aggregate level. No estimates were made for detailed product levels.

The countries, as the result of discussions about long-term solutions to the problem, agreed in a July 1987 Memorandum of Understanding to a more complete solution to the problem. Each country would use the other country's import-detail data to compile its export statistics. As a result, both countries would substantially improve their export statistics while markedly reducing costs. In addition, the exchange would allow both countries to eliminate the requirement for export documents. In the United States this would result in the elimination of approximately 2.5 million export documents annually.

After two years of intensive work to align the two statistical systems, this proposal finally become reality with the release of January 1990 statistics, when both countries began full use of counterpart import data to compile their export statistics.

\subsubsection{Export Port Audits}

The estimates of undocumented exports to Canada have led to questions as to the extent to which exports to other countries might also be undercounted. In order to measure possible undercount, the Census Bureau began in late 1988 to conduct a series of export port audits.

In cooperation with the Customs Service, the Census Bureau selected a sample of ten major ports for audit. The ports included four airports, four vessel ports, and two Mexican border ports. The teams conducting the audits consisted of staff from the Census Bureau and the Customs Service Washington headquarters working with Customs officials in the local ports. Because of differences in the clearance procedures and documentation for the various methods of transport, different auditing techniques had to be developed for air, vessel, and overland ports. Audit teams detected nonfiling of export documents by conducting examinations of the merchandise and accompanying documentation before the exporting carrier left the country.

Joint Census Bureau-Customs Service audit teams used this "preshipment" approach to conduct two-week audits of export operations at Seattle-Tacoma, Miami, Los Angeles, and New York's Kennedy international airports. These four airports account for over 60 percent of the value of U.S. air exports.

The results of the airport audits, which were conducted over a five-month period ending in mid-May 1989, estimated undercoverage resulting from the failure of exporters or their agents to file the required export documents at $\$ 6.7$ billion, or about 7.2 percent of the value of merchandise exported by air in 1988. The undercoverage ranged from an estimate of almost 10 percent at New York to about 1.5 percent at Seattle-Tacoma. However, the small number 
of flights sampled, generally around 30 to 40 at each airport, coupled with some difficulties in obtaining necessary documentation, makes it necessary to consider these numbers to be estimates rather than precise measurements.

The audits, designed primarily to measure nonfiling, also uncovered some indications of undervaluation of export shipments, especially in Miami. This undervaluation seemed limited to shipments destined for countries with particularly high tariff structures. Documentation accompanying export shipments is often used as proof of value in the importing country, so this finding makes intuitive sense. However, since the audit procedures were not designed to measure undervaluation, the auditors were unable to accurately quantify the effect on the value of total exports by air. The Census Bureau and the Customs Service are discussing the possibility of a future valuation audit involving examinations of exporters' books to determine actual selling prices.

The next planned step was to have been audits of export truck movements at the Mexican border crossings of Laredo and El Paso, Texas. These two crossings account for over 50 percent of the value of exports to Mexico. A Census Bureau team conducted a two-day pilot study of the two sites to determine how the audits could be conducted. However, because of resource limitations in the 1990 and 1991 budgets, the Census Bureau delayed plans to begin full-scale audits of the two ports.

In the interim, the Census Bureau has planned a small pilot study of vessel operations at the port of Baltimore to determine how best to conduct future vessel audits. In the future, when resources permit, the Census/Customs audit teams hope to conduct audits of vessel export operations at the ports of Baltimore, New York, Los Angeles, and Miami. These ports account for over $\mathbf{6 5}$ percent of exports by vessel.

\subsubsection{Reconciliation Efforts with Other Countries}

Since exports from one country are mirrored by imports in another and vice versa, reconciliations are an excellent tool for analyzing trade statistics and for judging their validity. The reconciliation process not only provides the tools to uncover macroproblems, such as undercounts or problems with valuation, but also provides insight into microproblems, such as commodity misclassification or problems with definitions.

In an effort to view more of the U.S. trade statistics from this perspective, the Census Bureau has begun reconciliation studies with four of its major trading partners: Japan, the European Economic Community, South Korea, and Mexico.

In an April 1989 meeting in Ottawa, Canada, representatives from the U.S. Census Bureau, Statistics Canada, and the Statistical Office of the European Communities agreed to a tripartite reconciliation of trade data between the EEC and North America. The agencies targeted early 1991 for completion of the reconciliation.

Representatives from the Census Bureau and the Customs Service met with 
Japanese officials in Tokyo in July 1989 to lay groundwork for a reconciliation of Japanese and U.S. trade data. This meeting represented a significant breakthrough with the Japanese, who had spurned earlier attempts to initiate a reconciliation. After a series of meetings in Washington and Tokyo, preliminary reconciliation results were expected in late 1990 .

In accordance with agreements reached with South Korean officials during meetings in Washington and Seoul, Customs Service and Census Bureau staff also are undertaking a reconciliation of U.S.-Korean trade data. No specific completion dates have been agreed on yet.

Finally, after a meeting with Mexican officials in April 1990, agreements were reached to undertake a reconciliation of U.S.-Mexican trade data.

Two major issues involved in all of these reconciliations were not part of the Canadian reconciliations. First, with Canada there was no complication in sorting out trade between the two reconciling countries caused by entrepôt or intermediary countries. Second, timing differences, which were not a factor with Canada, are considerable in the case of U.S. trade with Europe and the Far East.

For these reasons it is questionable whether an actual substitution of import data for export data is reasonable to expect as an end product of reconciliation efforts with the EEC, Japan, and South Korea, as it was with Canada.

\subsubsection{Trade in Constant Dollars}

Monthly trade data are traditionally valued in nominal (current) dollar amounts, with volumes expressed in various units of physical measure. A valid criticism, which was often leveled at the nominal trade statistics, is that these data reflect the effects of price and currency fluctuations and therefore cannot be used to measure changes in real trade flows.

The Census Bureau formerly produced what were termed "unit value indexes." These indexes simply calculated unit values based on the values and quantities or weights reported on the import and export documents. Because these indexes did not take into consideration changes in product mix or quality, they made poor indexes for converting nominal dollars to constant dollars, and so were discontinued.

The Census Bureau's sister agency in the Commerce Department, the Bureau of Economic Analysis (BEA), made quarterly adjustments to the trade statistics to create constant dollar trade totals for use in the national accounts. Most of the price indexes used by BEA to perform these adjustments were created from Bureau of Labor Statistics (BLS) quarterly surveys of import and export prices. These indexes, however, could not be applied to monthly trade data.

Out of concern with this absence of monthly constant-dollar trade statistics, Congress in the 1988 Omnibus Trade and Competitiveness Act instructed the director of the Census Bureau, in conjunction with the director of BEA and the commissioner of BLS, to study the feasibility of creating monthly 
constant-dollar trade statistics consistent with the BEA quarterly constantdollar figures.

Even before passage of the trade bill, BLS, at the direction of the executive Office of Management and Budget (OMB), had begun to develop monthly price surveys of importers and exporters. ${ }^{2}$ As a result, BLS released the first set of monthly trade indexes for six broad product categories in February 1989.

In the months after BLS first began producing monthly price indexes, the Census Bureau and BEA worked to devise ways to use the monthly indexes while ensuring consistency between the constant-dollar series produced by the two agencies.

Effective with the January 1990 statistics, the Census Bureau began compiling constant-dollar trade data. These data are produced for the same enduse product categories used in the national accounts, and with only minor exceptions are the same as the indexed data used in the national accounts.

\subsection{Microissues}

A very important segment of the users of foreign trade statistics is concerned with microlevel data. For example, one influential user of the detailed product level import statistics is the Office of the United States Trade Representative. It uses the data to monitor and administer the U.S. trade programs, many of which operate at detailed product and country levels under complex statistical formulae.

What has the Census Bureau done to address the quality of the detailed statistics? Here are some recent and proposed changes.

\subsubsection{The International Harmonized System-A Common Product Classification}

The passage of the Omnibus Trade and Competitiveness Act of $1988 \mathrm{em}-$ powered the United States to legally adopt the International Harmonized System (HS) for classification of merchandise in international trade. This classification system is the product of over 12 years of work by the Brussels-based Customs Cooperative Council, to which the Customs Service, Census Bureau, and International Trade Commission are the U.S. representatives. The system has a root 6-digit classification structure, providing for over 5,500 unique product classifications. Signatory countries must adopt the basic 6digit structure but are free to add digits for national detail. The U.S. system has 10 digits and provides about 8,000 export and 13,000 import classifications.

The adoption of this system in January of 1989 brought the U.S. into line

2. These monthly surveys utilized a subsample of the BLS quarterly respondents. 
with most other industrial nations, who had already instituted it. Over 70 nations are now using the system, including all major U.S. trading partners.

The adoption of the system has many benefits. First, it allows comparisons of U.S. trade statistics with foreign trading partner statistics on a level never before attainable, that is, at the 5,500 root classes adopted by all signatory countries. This is an immense aid in conducting reconciliations of detailed bilateral trade statistics with U.S. trading partners, discussed earlier. Also, the HS requires metric measures of weight and quantity. In the past most international transactions were conducted in metric measure, while the U.S. generally required English measure. Confusion often resulted.

Second, the system provides a widely used common classification system. For the first time it allows U.S. imports and exports to be reported on the same basis at a considerably detailed level. In addition, the Census Bureau has worked to align the Standard Industrial Classification (SIC) with the HS, allowing better comparisons of trade and production statistics. International statistical organizations such as the U.N. Statistical Office also are using the HS in structuring their international classification systems, such as the Standard International Trade Classification (SITC) and International Standard Industrial Classification (ISIC).

Finally, because U.S. shippers are using one system to trade internationally, the reporting of product classifications has been improving.

\subsubsection{New Data Elements}

In 1985 a rare opportunity allowed the Census Bureau to add new statistical data elements to the import and export documents simultaneously. Although resources did not exist at the time to compile statistics on the new information, the Census Bureau petitioned the Customs Service to add the new elements to the import entry documents, which it was in the process of revising. At the same time, the Census Bureau added new elements to the Export Declaration, a Commerce Department document, which was also being modified.

The new data elements were ones that had long been sought by U.S. data users: a unique identifier of the exporter or importer, the U.S. state of origin or destination of the shipment, and an indication of whether the transaction was between related parties (parent and subsidiary).

Although the Census Bureau was not successful in obtaining direct funding for the data elements, it was successful in getting sponsorship of some elements from other U.S. Government agencies and from interested private subscribers.

\section{State and Regional Trade Data}

For nearly two hundred years, trade data in the United States has dealt with flows of trade in terms of countries of destination or origin and U.S. Customs ports of exit or entrance. Only in recent years has there been general interest in data measuring the impact of foreign trade on the U.S. states that produce 
exports and consume imports. Global economic trends and their ramifications now touch all states and make it relevant to raise questions that few are concerned about in the past: What and how much does a state export or import? Where do these exports go or imports come from? How many exporters or importers are located in a state?

In an effort to address these questions, the Census Bureau produced with subscriber funding a set of three special reports for 1987 and 1988. These reports, available on tape, detail exports for the following:

(i) Nine geographic regions, with 4-digit SITC product detail and countries of destination.

(ii) The 50 states, with 2-digit SICs and countries of destination.

(iii) Total exports for each of the 50 states, showing port of exit and country of destination for each mode of transport.

Aside from the above, aggregate state export and import totals were made available for 1987 and 1988 in the regular Census Bureau foreign trade publication, the FT990, "Highlights of U.S. Imports and Exports"; and for 1989 and 1990, in the supplement to the monthly Commerce Department press release on U.S. merchandise trade.

Publication of import statistics by state, however, has been suspended pending improvements in the collection methodology. It appears that the reported states of destination quite often reflect importer or broker offices responsible for the account paperwork rather than the state for which the merchandise is actually destined. Large gateway states, such as New York and California, incorrectly receive credit for extremely large segments of imports. The wording on the Customs import document and the instructions for its preparation need to be reworked to prevent this bias.

The export origin data has some similar biases. Homogeneous nonmanufactured products, such as bulk grains and ores, are particularly troublesome. Since these commodities often come from various locations and are indistinguishable when mixed, the exporter is often unable to provide a true state of origin.

In order to improve the usefulness and reliability of the statistics, state export totals have been split into two categories, manufactured goods and nonmanufactured goods (including agricultural, mining, and other raw materials). It is expected that this distinction between manufactured and nonmanufactured products will yield a much more reliable picture for the manufactured products from a "point of origin" perspective.

\section{Exporter Characteristics}

The addition of a field on the revised export document for the exporter's Employer Identification Number (EIN) has provided the Census Bureau with the first opportunity to construct statistics on the characteristics of the exporting community. Simple questions, such as how many firms export, the fre- 
quency with which each exports, and the size of the average shipment, have long remained unanswered.

Using funding provided by BLS and the Commerce Department's International Trade Administration, the Census Bureau recently produced the first sets of statistics profiling the exporter community. For the first time, a count of active exporters (100,000 in any given month) is available, along with the frequency of shipments by these exporters and the dollar value of shipments. These data are only the beginning of statistics on the characteristics of exports.

The Census Bureau also is seeking to develop an "Exporter Data Base" (EDB) by using the exporter number to aid in linking commodity-export data available from the monthly trade statistics with business-establishment characteristics available from the Census Bureau quinquennial Economic Census. This link will open an important flow of data on U.S. firms and their production as related to exports.

Another and perhaps most significant use for the EDB is a mailing list to contact problem exporters. Until now, no complete automated exporter file has existed for informing exporters of general information about export reporting or for contacting specific exporters about problems with the data they have supplied.

\section{Related Party Trade}

Although the Census Bureau has received numbers of inquiries concerning the availability of data on trade between related and nonrelated firms, the Census Bureau has no resources with which to compile this information. A number of federal agencies, as well as some private data users, however, have expressed interest in this information, and we hope in the future to secure funding to compile some limited aggregate-level data.

\section{Seasonal Adjustment of Detail Data}

In January 1990, in order to align Census Bureau methods more closely with those used in the national accounts, product level adjustments were extended beyond the 6 broad end-use categories to the much more detailed 5 digit end-use level, with over 70 series adjusted.

In addition, the Census Bureau, since it has received repeated requests to extend seasonal adjustment to even more detailed levels of data, is working to extend seasonal adjustment to import and export totals at the country and world levels. If resources allow, we expect these new adjustments in 1991 .

\subsection{The Future}

The Census Bureau's foreign trade statistics program has repeatedly been forced to do more with little or no increase in resources. Although the Census Bureau asked for $\$ 1.8$ million in increased funding for the foreign trade statis- 
tics program in FY 1990, this funding increase was never approved. Funding requests were denied or substantially reduced in each of the previous six fiscal years.

In response, the Census Bureau is pursuing a number of initiatives which it thinks will not only reduce costs but maintain or improve the quality of the statistics.

\subsubsection{Expanded Automated Collection}

The Census Bureau views automated collection of data as having two major benefits in the current era of limited resources. First, it saves on processing costs by tapping automated sources which already exist in the trade community. Money saved by the automated collection can then be used elsewhere in the trade statistics program to increase quality and to improve or expand data products. Second, automation results in more accurate statistics, since the automated source data are generally more accurate than information currently captured from paper documents.

Over the last six years, the Customs Service has developed the Automated Commercial System (ACS), a giant computer telecommunications network designed to link all aspects of Customs activities (such as entry processing and cargo tracking) at all Customs ports throughout the United States.

Automated systems have progressed especially rapidly for imports. The Automated Broker Interface (ABI), which is part of ACS, provides electronic processing of import entry transactions for qualified computerized brokers and importers. Large-volume Customs brokers can submit information on import entries directly to the Customs Service via the ABI. These brokers receive priority handling and quick liquidation of their accounts from Customs. Brokers are now utilizing the ABI system at all major U.S. ports, and the system currently accounts for about 80 percent of all import transactions filed with Customs.

In 1983, the Census Bureau began working with Customs to develop a program to use ABI information for statistical purposes. The resulting system, the Census Interface, is a series of Census-developed programs residing in the Customs computers, which extract data from ABI, subject it to Census edits and validations, and prepare it for processing on Census computers.

In November 1987, after almost five years of development, testing, and quality checks, Census began extracting statistical data nationwide from the Customs system. At present about one million transactions monthly, or about 80 percent of all import transactions, are extracted from the Customs system. The Customs Service anticipates that by 1992,90 percent of all imports will be processed through the $\mathrm{ABI}$.

In addition, many of the Census Bureau's statistical edits have been programmed in the Customs Service system. Failures of the statistical edits require resolutions by importers or brokers before the data will be accepted by Customs. As a result, automated data arriving at the Census Bureau is more 
accurate and requires less additional processing.

The Census Bureau also collects about 50 percent of export data directly from automated exporters, brokers, and carriers through its own Automated Export Reporting Program (AERP) and from Statistics Canada via the U.S.Canada data exchange.

The AERP Program has been slow to grow, with recent increases barely keeping ahead of expansions in trade. In an effort to increase the segment of export trade which is collected electronically, the Census Bureau has entered into discussions with the Customs Service about using the ACS to collect export data. Although initial resource outlays to create an export subsystem are substantial, the prospect of creating a national automated system for exporters and export brokers is very attractive.

\subsubsection{Fees For Data Products}

Recently the Census Bureau has been successful in initiating new data products for limited groups by having users provide the necessary resources, through direct user fees, subscriptions, or contracts.

Two major new data series, exports by state and exporter characteristics, have been launched in this manner. The Census Bureau will continue to seek user funding for new series, such as related-party trade.

\subsubsection{Independent Review of the Current Statistical System}

In an effort to better chart the future of the trade statistics program, the Census Bureau entered into a contract in 1988 with the Committee on National Statistics of the National Academy of Sciences for the establishment of a panel on foreign trade statistics, to conduct a study of the current system of collecting, processing, and reporting foreign trade statistics. The study, which is being jointly funded by the Census Bureau, the Customs Service and the Commerce Department's International Trade Administration and Bureau of Economic Analysis, is scheduled for completion in late 1991.

A distinguished panel, comprised of academic, business, and financial experts, began work on the study in June 1989. The panel is drawing on contacts with relevant federal agencies and private organizations in drafting its report and recommendations.

In conducting the study, the panel has been asked to consider the following issues:

(i) What trade data are needed? In particular, what domestic and foreign trade data are needed to assess our international economic position? What new uses can we expect for current and projected trade data? What new data products should be developed?

(ii) How should the data be obtained? Can a sample-based collection approach provide needed data? Should it replace or supplement existing systems?

(iii) How good are existing data? Are trade data adequate for their actual and 
intended uses? Will particular quality improvements help trade data users? Are data items collected but not fully utilized? What product changes might enhance data use? Could changes in schedule or sequence make trade data more useful?

(iv) How can the existing data system be improved? How can new technologies be applied to data collection and processing? What educational and other outreach methods might improve data collection or encourage better data use?

The Bureau expects this review to provoke independent thoughts and suggestions useful in planning and shaping the future of the trade statistics program.

\section{References}

Farrell, Michael G., and Anthony Radspieler. 1989. Census Bureau State-by-State Foreign Trade Data: Historical Perspectives; Current Situation; Future Outlook. U.S. Bureau of the Census. May 15. Washington, D.C.

General Accounting Office, Staff 1989. Merchandise Trade Statistics: Some Observations. Briefing Report to the chairman, Panel on Foreign Trade Statistics, Committee on National Statistics, National Academy of Sciences. April 17. Washington, D.C.

Puzzilla, Kathleen, J., Anthony Radspieler, and Bruce C. Walter. 1988. Changes in Foreign Trade Statistics at the Census Bureau. Paper presented to the Census Advisory Committee of the American Statistical Association. October 13. Washington, D.C. U.S. Bureau of the Census.

Waite, Charles A. 1988. Census Bureau Trade Data-Program Overview, Developments, and Directions. Briefing presented to the Washington Export Council. April 28. Washington, D.C. U.S. Bureau of the Census.

1989. Perspectives and Issues--Merchandise Trade Data. Briefing presented to the Panel on Foreign Trade Statistics, Committee on National Statistics, National Academy of Sciences. June 9. Washington, D.C.

\section{Comment David J. Klock}

The Walter paper is a useful status report. I am impressed with the scope of the efforts described in the paper to improve the quality of the basic monthly statistics on value of U.S. exports and imports, while at same time responding to a wide range of demands for more detail, especially given resource constraints. My remarks will focus on recent and potential improvements to the

David J. Klock is Director, Office of Balance of Payments Analysis, U.S. Treasury Department. Mention of the author's affiliation is for identification only. Nothing in this comment should be taken as reflecting official U.S. Government or Treasury Department policy. 
aggregate-value or macro data discussed in the first half of the paper. I will touch on price/volume issues at the end of this comment.

The paper discusses three broad aspects of "quality"-accuracy, ${ }^{1}$ timeliness, and availability of a range of underlying detail to meet needs of different audiences. The first two criteria are most relevant to the macro data.

Timeliness is a subjective criterion, and is in part the product of a tradeoff between promptness and accuracy. The specific instance discussed in the paper-accepting a delay in availability of data from four to six weeks, in exchange for a reduction in "carryover" by the substantial magnitudes indicated-seems to be a pretty good deal, especially since it allows for resumption of seasonal adjustment. ${ }^{2}$ If seasonal adjustment can be extended to the geographic detail, so much the better. But at least two caveats might be entered. While availability of seasonally adjusted data is welcome, it would be very useful to have a little clearer indication as to what the criteria are for seasonal adjustment, and perhaps as to how stable the actual monthly seasonal factors are. Furthermore, six weeks clearly is close to the limit of what can be considered current data, given the time frame of some important consumerspolicymakers, GNP estimators, and financial markets.

As regards accuracy, the paper points out a differential in the tightness of the collection net for exports as opposed to imports ${ }^{3}$ and suggests several potentially valuable programs to improve export coverage, supplementing the Canadian reconciliation program.

But the Canadian example may be unique. I share Walter's skepticism concerning potential utility of a Canada-style reconciliation exercise with the EEC and Japan, in view of timing and entrepôt problems. Generally, it is interesting that work seems more advanced on checking exports to these countries; I would have thought Mexico, the trade situation with which is partly, though not entirely, analogous to that with Canada, might offer more potential ${ }^{4}$ The paper clearly brings out the importance of aggressively pursuing the

1. To reduce the danger of rediscovering the wheel, I took this opportunity to go back to Oskar Morgenstern's classic, On the Accuracy of Economic Observations (2d ed. Princeton, 1963).

2. This conclusion assumes that we can infer the degree to which the need for subsequent revisions has been reduced from the degree to which carryover has been reduced, i.e., that carryover was the dominant factor necessitating subsequent revision.

3. Inter alia, raw data are collected by Customs. As the paper makes clear, there is very close, continuous interaction between Customs and Census in the data collection effort. But compilation of trade data is not the sole or primary Customs mission, and it goes without saying that Customs also faces resource constraints. Morgenstern (p. 25l) notes "some data that become available from Government agencies are a by-product of their administrative functions. This is frequently a strong reason to suspect the quality of data obtained in this manner."

4. As an aside on this issue, I would have thought export overvaluation to Latin America would be at least as likely as the possible tendency toward undervaluation noted in the paper, especially if U.S. export documents are used as proof of valuation in the importing country. Overinvoicing of imports and underinvoicing of exports are classic vehicles for capital flight. But perhaps the much-noted internationalization and liberalization of markets has made more direct and convenient channels available. 
export audit program. Census's limited ability to do so is just one more example of how the budget imbroglio creates havoc with government priorities and decision making.

Walter notes that the 1988 Trade Act, whatever its other merits or defects, made several significant contributions to quality of the published trade data. Most economic analysis, at least that which goes beyond the "who struck John" level, requires data on prices and quantities. The 1988 Trade Act brought together the relevant players in the U.S. Government with a mandate to "conduct a study to determine the feasibility of publishing an index" of monthly trade volumes. I am not convinced of a crying need for monthly trade volume numbers, for several reasons. ${ }^{5}$ The hope is that there might be enough commonality that the process of generating monthly volume (and perforce, price) data would contribute to resolution of some of the remaining problems with existing quarterly data as well. Clearly, improvement of the available price data is a top-priority quality issue, ${ }^{6}$ for quarterly as well as monthly data. The Meade paper (ch. 2 in this volume) highlights what almost certainly is the most serious problem in this area. But this issue is much bigger than just deflation of the trade data. As is widely recognized, it gets into basic questions of measuring U.S. economic performance. Despite the inevitable resource constraints, hopefully the effort to develop monthly price series doesn't just carry over "best" existing methodology without at least another look.

5. They are likely to be inherently "noisy," even after seasonal adjustment; there is a danger that scarce resources will be diverted from maintenance and improvement of the existing quarterly series that most modelers and analysts use in their standard trade models; and this will be one more number for the markets to think they need to react to.

6. According to Morgenstem (p. 181), "A study of the accuracy of economic observations, however rudimentary, must deal at least briefly with the most basic economic and statistical variable of all, price" (italics in original). 